\title{
Quality of cause-of-death reporting using ICD-10 drowning codes: a descriptive study of 69 countries
}

\author{
Tsung-Hsueh Lu', Philippe Lunetta², Sue Walker ${ }^{3^{*}}$
}

\begin{abstract}
Background: The systematic collection of high-quality mortality data is a prerequisite in designing relevant drowning prevention programmes. This descriptive study aimed to assess the quality (i.e., level of specificity) of cause-of-death reporting using ICD-10 drowning codes across 69 countries.

Methods: World Health Organization (WHO) mortality data were extracted for analysis. The proportion of unintentional drowning deaths coded as unspecified at the 3-character level (ICD-10 code W74) and for which the place of occurrence was unspecified at the $4^{\text {th }}$ character (.9) were calculated for each country as indicators of the quality of cause-of-death reporting.

Results: In 32 of the 69 countries studied, the percentage of cases of unintentional drowning coded as unspecified at the 3 -character level exceeded $50 \%$, and in 19 countries, this percentage exceeded $80 \%$; in contrast, the percentage was lower than $10 \%$ in only 10 countries. In 21 of the 56 countries that report 4-character codes, the percentage of unintentional drowning deaths for which the place of occurrence was unspecified at the $4^{\text {th }}$ character exceeded 50\%, and in 15 countries, exceeded 90\%; in only 14 countries was this percentage lower than $10 \%$.
\end{abstract}

Conclusion: Despite the introduction of more specific subcategories for drowning in the ICD-10, many countries were found to be failing to report sufficiently specific codes in drowning mortality data submitted to the WHO.

\section{Background}

Drowning is an important but neglected global health issue [1-4]. The systematic collection of high-quality mortality data about the environmental events and circumstances leading to a case of drowning is a prerequisite to designing relevant drowning prevention programmes [5,6]. Almost all countries collect, classify and tabulate cause-of-death data according to the same standard procedure (i.e., using the International Statistical Classification of Diseases and Related Health Problems (ICD) published by the World Health Organization (WHO)) [7]. The update from the Ninth Revision (ICD-9) to the Tenth Revision (ICD-10) entailed significant changes in the classification of unintentional drowning [8]: the ICD-9 emphasised details regarding

\footnotetext{
* Correspondence: s.walker@qut.edu.au

${ }^{3}$ National Centre for Health Information Research and Training, School of Public Health, Queensland University of Technology, Victoria Park Road, Kelvin Grove, Australia
}

the nature of the recreational activity undertaken at the time of the event; in contrast, the ICD-10 highlights details about the nature of the body of water (e.g., bathtub, swimming pool or natural water) and the mechanism of drowning (e.g., while in water versus following a fall into water) (Table 1).

Despite the innovative expansion of the classification scheme in the ICD-10 for unintentional drowning, little is known about the current quality of cause-of-death reporting using ICD-10 codes in most countries. As noted in the World Report on Child Injury, even in relatively advanced countries, information regarding the place in which drowning occurs is poorly documented on death certificates [[9], p.61]. A recent study also indicates that of the 52 countries in the WHO European region, only 23 use 4th-character subdivisions and only 3 countries had high-quality data on the place of occurrence of injuries [10]. This present study aimed to assess the quality (i.e., level of specificity) of cause-of-death 
Table 1 Sub-categories of ICD-9 and ICD-10 codes for unintentional drowning (online ICD-10 codes can be accessed at http://apps.who.int/classifications/apps/icd/icd10online).

\begin{tabular}{llcl}
\hline ICD-9 code & & ICD-10 code & \\
\hline E910 & Accidental drowning and submersion & W65-W74 & Drowning and submersion \\
E910.0 & while water-skiing & W65 & while in bathtub \\
E910.1 & while engaged in other sport or recreational activity with diving equipment & W66 & following fall into bathtub \\
E910.2 & while engaged in other sport or recreational activity without diving equipment & W67 & while in swimming pool \\
E910.3 & while swimming or diving for purposes other than recreation or sport & W68 & following fall into swimming pool \\
E910.4 & in bathtub & W69 & while in natural water \\
E910.8 & Other & W70 & following fall into natural water \\
E910.9 & unspecified place of occurrence code & W73 & other specified
\end{tabular}

In the ICD-10, the following fourth-character sub-divisions serve to identify the place of occurrence of the external cause where relevant:

.0 Home

.1 Residential institution

.2 School, other institution, or public administrative area

.3 Sports and athletics area

.4 Street or highway

.5 Trade and service area

.6 Industrial or construction area

.8 Other specified place

.9 Unspecified place

reporting using ICD-10 drowning codes across countries.

\section{Methods}

Data were extracted from the WHO mortality database for analysis [11]. As of August 2009, 146 countries submitted mortality data to the WHO, of which 17 used only 3-character ICD-10 codes and 84 used 4-character ICD-10 codes. The ICD-10 codes for unintentional drowning are W65-W74 (Table 1). We excluded suicide by drowning (ICD-10 code X71), homicide by drowning (ICD-10 code X92), and cases of drowning of undetermined intent (ICD-10 code Y21), because no specific sub-categories exist for these codes in the ICD-10.

To ensure statistical stability in the calculation of percentages, we included only those countries with more than 20 reported unintentional drowning deaths; thus, a total of 69 countries were included in the final analysis. To illustrate the magnitude of the mortality rates of unintentional drowning for each country, we first computed the age-adjusted drowning death rate (deaths per 100000 people) for each country using the WHO standard population structure. The age groups used for computing age-adjusted death rates were 0-14, 15-24, 25-44, 45-64 and 65+ years of age. Of the 69 countries included in the analysis, only 43 countries had population data from which the death rate could be calculated.

We then calculated two indicators of the quality (i.e., level of specificity) of cause-of-death reporting using ICD-10 codes for cases of unintentional drowning. The first indicator was the proportion of unintentional drowning deaths (ICD-10 codes W65-W74) coded as unspecified at the 3-character level (ICD-10 code W74) (Table 1); the second was the proportion of unintentional drowning deaths in which the place of occurrence was unspecified at the $4^{\text {th }}$ character (.9) (Table 1). In other words, the higher the percentage of cases in which an unspecified code is reported, the poorer the quality of cause-of-death reporting.

\section{Results}

Of the 43 countries with population data available for the calculation of age-adjusted death rates, five countries had a drowning death rate higher than 5 per 100 000: 9.8 in Lithuania, 9.6 in Latvia, 7.1 in Thailand, 6.9 in the Republic of Moldova, and 5.4 in Kyrgyzstan (Table 2). In 32 of the 69 countries studied in total, the percentage of cases of unintentional drowning coded as unspecified at the 3-character level exceeded 50\%, and in 19 countries, this percentage exceeded $80 \%$; in contrast, this proportion was lower than $10 \%$ in only 10 countries. In 21 of the 56 countries that report 4-character codes, the proportion of unintentional drowning deaths in which the place of occurrence was unspecified at the fourth character exceeded $50 \%$, and in 15 countries, the percentage exceeded $90 \%$; in only 14 countries was this percentage lower than $10 \%$. We found a large discrepancy between countries with regard to the unspecified codes at the 3-character level and the $4^{\text {th }}$ character code; for example $99 \%$ vs. $0 \%$ respectively in El Salvador, and, in contrast, $0 \%$ versus $100 \%$ in $\mathrm{New}$ Zealand. 
Table 2 Number and age-adjusted death rate (per 100000 people) of unintentional drowning deaths and the proportion of drowning deaths coded as 'unspecified' in each country, ranked by the percentage of 'unspecified' cases at the 3-character level according to the WHO mortality database, August 2009.

\begin{tabular}{|c|c|c|c|c|c|}
\hline Country & $\begin{array}{r}\text { The latest } \\
\text { available } \\
\text { year }\end{array}$ & $\begin{array}{r}\text { No. of deaths from } \\
\text { unintentional } \\
\text { drowning }\end{array}$ & $\begin{array}{r}\text { Age- } \\
\text { adjusted } \\
\text { drowning } \\
\text { death rate }\end{array}$ & $\begin{array}{r}\% \text { of drowning deaths classified } \\
\text { as unspecified at the 3-character } \\
\text { level }\end{array}$ & $\begin{array}{r}\% \text { of drowning deaths classified } \\
\text { as unspecified at the 4th } \\
\text { character }\end{array}$ \\
\hline Suriname & 2005 & 34 & NA & 100 & 94 \\
\hline Kuwait & 2002 & 20 & 1.7 & 100 & 90 \\
\hline Guatemala & 2006 & 87 & NA & 100 & 61 \\
\hline Thailand & 2002 & 4218 & 7.1 & 100 & 100 \\
\hline Peru & 2000 & 656 & NA & 100 & 96 \\
\hline El Salvador & 2006 & 238 & NA & 99 & 0 \\
\hline Guyana & 2005 & 90 & NA & 99 & 100 \\
\hline Israel & 2005 & 48 & 0.7 & 98 & 100 \\
\hline Belize & 2001 & 41 & NA & 98 & 100 \\
\hline Mauritius & 2007 & 38 & 3.1 & 97 & 100 \\
\hline Uruguay & 2004 & 71 & NA & 97 & 44 \\
\hline South Africa & 2005 & 147 & NA & 96 & NA \\
\hline Costa Rica & 2006 & 132 & NA & 94 & 6 \\
\hline Taiwan & 2007 & 486 & 1.9 & 89 & NA \\
\hline Georgia & 2001 & 45 & 0.9 & 89 & NA \\
\hline Chile & 2005 & 488 & NA & 89 & 1 \\
\hline Bahamas & 2002 & 42 & NA & 86 & 52 \\
\hline $\begin{array}{l}\text { Serbia and } \\
\text { Montenegro, } \\
\text { Former }\end{array}$ & 2002 & 94 & 1.2 & 84 & 11 \\
\hline France & 2006 & 1008 & 1.3 & 82 & 53 \\
\hline Réunion & 2005 & 20 & NA & 80 & 55 \\
\hline Italy & 2006 & 378 & 0.6 & 75 & 49 \\
\hline Paraguay & 2004 & 99 & NA & 69 & 21 \\
\hline Spain & 2005 & 494 & 1.0 & 66 & 47 \\
\hline Haiti & 2003 & 20 & & 65 & 45 \\
\hline Norway & 2006 & 65 & 1.1 & 63 & 100 \\
\hline Argentina & 2005 & 563 & NA & 60 & 17 \\
\hline $\begin{array}{l}\text { Republic of } \\
\text { Moldova }\end{array}$ & 2007 & 261 & 6.9 & 60 & 0 \\
\hline Kyrgyzstan & 2006 & 270 & 5.4 & 57 & 23 \\
\hline Netherlands & 2007 & 76 & 0.4 & 57 & 3 \\
\hline Egypt & 2000 & 1591 & NA & 54 & NA \\
\hline Uzbekistan & 2005 & 1042 & 3.9 & 52 & NA \\
\hline Azerbaijan & 2007 & 62 & 0.8 & 52 & NA \\
\hline Romania & 2007 & 992 & 4.4 & 50 & 18 \\
\hline Serbia & 2007 & 115 & 1.4 & 46 & NA \\
\hline Mexico & 2006 & 2310 & NA & 46 & 21 \\
\hline Colombia & 2005 & 1019 & NA & 44 & 16 \\
\hline Ecuador & 2006 & 521 & NA & 44 & 21 \\
\hline Czech Republic & 2007 & 182 & 1.5 & 44 & 31 \\
\hline Denmark & 2006 & 46 & 0.7 & 43 & 100 \\
\hline Germany & 2006 & 418 & 0.4 & 43 & 31 \\
\hline Brazil & 2005 & 6171 & NA & 42 & 26 \\
\hline $\begin{array}{l}\text { Republic of } \\
\text { Korea }\end{array}$ & 2006 & 757 & 1.5 & 40 & NA \\
\hline Venezuela & 2005 & 590 & NA & 38 & 17 \\
\hline Sweden & 2006 & 106 & 0.9 & 38 & 100 \\
\hline
\end{tabular}


Table 2: Number and age-adjusted death rate (per 100000 people) of unintentional drowning deaths and the proportion of drowning deaths coded as 'unspecified' in each country, ranked by the percentage of 'unspecified' cases at the 3-character level according to the WHO mortality database, August 2009. (Continued)

\begin{tabular}{|c|c|c|c|c|c|}
\hline Nicaragua & 2005 & 196 & NA & 37 & 97 \\
\hline Belgium & 1999 & 54 & 0.5 & 37 & NA \\
\hline Poland & 2006 & 1031 & 2.5 & 34 & 52 \\
\hline Canada & 2004 & 251 & 0.8 & 32 & 100 \\
\hline Croatia & 2006 & 78 & 1.3 & 32 & 36 \\
\hline Austria & 2007 & 75 & 0.8 & 27 & 21 \\
\hline $\begin{array}{l}\text { United } \\
\text { Kingdom }\end{array}$ & 2007 & 224 & 0.4 & 24 & 2 \\
\hline $\begin{array}{l}\text { United States } \\
\text { of America }\end{array}$ & 2005 & 3582 & 1.2 & 23 & 10 \\
\hline Puerto Rico & 2005 & 37 & NA & 19 & 0 \\
\hline Australia & 2004 & 198 & 1.0 & 19 & 12 \\
\hline Estonia & 2005 & 59 & 4.1 & 17 & NA \\
\hline Hungary & 2005 & 192 & 1.7 & 14 & 2 \\
\hline $\begin{array}{l}\text { Trinidad and } \\
\text { Tobago }\end{array}$ & 2002 & 44 & 3.4 & 14 & 11 \\
\hline $\begin{array}{l}\text { Dominican } \\
\text { Republic }\end{array}$ & 2004 & 29 & NA & 10 & 100 \\
\hline Ireland & 2007 & 51 & 1.1 & 10 & 4 \\
\hline Japan & 2007 & 5966 & 2.5 & 9 & 7 \\
\hline Slovenia & 2007 & 28 & 1.1 & 7 & NA \\
\hline $\begin{array}{l}\text { Hong Kong } \\
\text { SAR }\end{array}$ & 2007 & 43 & NA & 7 & 0 \\
\hline Slovakia & 2005 & 138 & 2.4 & 7 & NA \\
\hline Lithuania & 2007 & 381 & 9.8 & 6 & 1 \\
\hline Panama & 2006 & 120 & NA & 5 & 9 \\
\hline Cuba & 2006 & 253 & NA & 1 & 2 \\
\hline Latvia & 2007 & 237 & 9.6 & 1 & NA \\
\hline Finland & 2007 & 143 & 2.1 & 1 & 100 \\
\hline New Zealand & 2005 & 56 & 1.4 & 0 & 100 \\
\hline
\end{tabular}

\section{Discussion}

Using the percentage of cases coded as unspecified as an indicator of the quality of cause-of-death reporting for unintentional drowning deaths using ICD-10 codes, our findings indicate that in one in seven of the countries studied the quality of cause-of-death reporting was less than acceptable. Factors associated with the coding of unintentional drowning deaths as unspecified may result from different factors, such as a lack of specific information regarding the circumstances that led to the drowning, the inadequate collection of primary data owing to insufficient police and medico-legal investigation, and incompleteness or errors during the death certification and coding process. In addition, countries may focus on different aspects of drowning for their prevention programmes and therefore require differing levels of specificity in the ICD-10 codes. For example, El Salvador may require more details about the place of occurrence of the drowning at the $4^{\text {th }}$ character code level and place less emphasis on the body of water, whereas in New
Zealand the focus may be more on coding information about the body of water involved and less on the place of occurrence. Additionally, the use of a national modification of the ICD-10 in New Zealand may have had an effect on reporting of place of occurrence, as the modification utilizes different codes compared with the international version of the ICD-10.

An international comparison study indicated that the main reason for which injury-related deaths are coded as unspecified is that medical certifiers (including medical examiners and coroners) fail to report sufficiently detailed information on the death certificates to allow coders to assign specific codes [12]. Another study also indicated that despite the legal requirement that all unnatural deaths be subjected to forensic investigation by a physician in Thailand, the cause of death is usually described in terms of symptoms rather than attributed to a specific underlying cause, because physicians are reluctant to provide specifics and risk involvement in legal proceedings [13]. Parish also suggests that a lack of 
standardised methods and inadequate training for certifiers, medical examiners and coroners in addition to a lack of adequate resources for conducting investigations of deaths results in variations in the quality of mortality data for injury surveillance [14]. More efforts should focus on training medical certifiers to report specific information relevant to injury prevention on death certificates.

The circumstances and environments that result in drowning deaths differ between countries according to the reported ICD codes. The differentiation of mechanisms of drowning deaths into 'while in water' from 'following a fall into water' is one of the important changes in the ICD-10. The two circumstances have different implications for injury prevention. For instance, drowning while in water would mandate the promotion of personal flotation devices and ensuring adequate supervision, whereas drowning following a fall into water would underscore the value of effective barriers. A percentage of drowning deaths coded as unspecified that was high and skewed to one particular mechanism of drowning would bias comparisons of mortality between the two mechanisms. We recommend caution in interpreting the possible effects of unspecified coding on the comparison of international drowning mortality data by sub-category.

One of the limitations of this study was our use of secondary mortality data from the WHO, which lacks metadata about how each country collects information concerning circumstances resulting in and the mechanisms of unintentional drowning as well as the process of death certification and coding. The second limitation was that many countries do not yet use the ICD-10, and some countries had no available population data; having such data available would have contributed to a more complete picture of the global status. The third limitation was the difficulty in defining 'high quality' according to the percentage of cases coded as unspecified; in this study, we used a cut-off of $10 \%$. There is no internationally recognized standard to calculate the quality of coded data. This study is simply an initial assessment of the global status of the provision of specific information in cases of death due to unintentional drowning, and further studies are needed to explore the exact reasons for the high number of cases of unintentional drowning coded as unspecified in various countries.

\section{Conclusion}

In conclusion, despite the introduction of more specific subcategories for drowning in the ICD-10, which would provide better information for the design of prevention programmes, the findings of this study illustrate that many countries fail to report sufficiently specific codes in drowning mortality data submitted to the WHO.

\section{Acknowledgements}

The WHO provided the mortality and population data. The analyses, interpretations, and conclusions of this study are solely those of the authors; the $\mathrm{WHO}$ is responsible only for the provision of the original data. This study was supported by grants from the National Science Council of Taiwan (NSC95-2314-B-006-093) and the Department of Health of Taiwan (DOH96-TDM113-049).

\section{Author details}

${ }^{1}$ NCKU Research Center of Health Data and Institute of Public Health, College of Medicine, National Cheng Kung University, No. 1, Dah Hsueh Road, Tainan, Taiwan. ${ }^{2}$ Hjelt Institute, Department of Forensic Medicine, University of Helsinki, and National Institute for Health and Welfare, Injury Prevention Unit, 00300 Helsinki, Finland. ${ }^{3}$ National Centre for Health Information Research and Training, School of Public Health, Queensland University of Technology, Victoria Park Road, Kelvin Grove, Australia.

\section{Authors' contributions}

THL initiated this study and conducted the primary data analyses. THL, PL and SW participated equally in the interpretation of the results and critically commented upon and drafted the manuscript. All the authors have read and approved the final version of the manuscript.

\section{Competing interests}

The authors declare that they have no competing interests.

Received: 27 October 2009 Accepted: 8 April 2010

Published: 8 April 2010

\section{References}

1. Brenner RA: Childhood drowning is a global concern. BMJ 2002 324:1049-1050.

2. Peden MM, McGee K: The epidemiology of drowning worldwide. Inj Control Saf Promot 2003, 10:195-199.

3. Rahman A, Giashuddin SM, Svanström L, Rahman F: Drowning - a major but neglected child health problem in rural Bangladesh: implications for low income countries. Int J Inj Contr Saf Promot 2006, 13:101-105.

4. Branche $C$, van Beeck E: The epidemiology of drowning. Handbook on Drowning Berlin Heidelberg, Germany: SpringerBierens JJLM 2006, 41-75.

5. Salmomez F, Vincent JL: Drowning: a review of epidemiology, pathophysiology, treatment and prevention. Resuscitation 2004 63:261-268.

6. Quan L, Bennett EE, Branche CM: Interventions to prevent drowning. Handbook of Injury and Violence Prevention New York: SpringerDoll LS, Bonzo SE, Mercy JA, Sleet DA 2007, 81-96.

7. World Health Organization: International Statistical Classification of Diseases and Related Health Problems, Tenth Revision. Geneva: World Health Organization 1992.

8. Langley JD, Chalmers DJ: Coding the circumstances of injury: ICD-10 a step forward or backwards? Inj Prev 1999, 5:247-253.

9. Taneja G, van Beeck E, Brenner R: Drowning. World Report on Child Injury Prevention Geneva, Switzerland: World Health Organization PressPeden M, Oyegbite K, Ozanne-Smith J, Hyder AA, Branche C, Rahman AKMF, Rivara F, Bartolomeos K 2008, Chapter 3:59-78.

10. Suarez-Garcia I, Sethi D, Hutchings A: Mortality due to injuries by place of occurrence in the European region: analysis of data quality in the WHO mortality database. Inj Prev 2009, 15:275-277.

11. World Health Organization: Download the detailed data files of the WHO Mortality Database.[http://www.who.int/whosis/mort/download/en/index. html], August 15, 2009.

12. Lu TH, Walker S, Anderson RN, McKenzie K, Björkenstam C, Hou WH: The proportion of injury deaths with unspecified external cause codes-a comparison of Australia, Sweden, Taiwan and the United States. Inj Prev 2007, 13:276-281. 
13. Tangcharoensathien V, Faramnuayphol P, Teokul W, Bundhamcharoen $\mathrm{K}$, Wibulpholprasert S: A critical assessment of mortality statistics in Thailand: potential for improvements. Bull World Health Organ 2006, 84:233-238.

14. Parrish G: Assessing and improving the quality of data from medical examiners and coroners. Proceedings of International Collaborative Effort on Automating Mortality Statistics, Volume I. Papers presented at the International Symposium on Injury Statistics, May 18-24, 1994 Bethesda, Maryland: National Center for Health Statistics 1995, 25:1-10.

\section{Pre-publication history}

The pre-publication history for this paper can be accessed here:http://www. biomedcentral.com/1471-2288/10/30/prepub

doi:10.1186/1471-2288-10-30

Cite this article as: Lu et al:: Quality of cause-of-death reporting using ICD-10 drowning codes: a descriptive study of 69 countries. BMC

Medical Research Methodology 2010 10:30.

\section{Submit your next manuscript to BioMed Central} and take full advantage of:

- Convenient online submission

- Thorough peer review

- No space constraints or color figure charges

- Immediate publication on acceptance

- Inclusion in PubMed, CAS, Scopus and Google Scholar

- Research which is freely available for redistribution

Submit your manuscript at www.biomedcentral.com/submit 